\title{
2
}

\section{The Good Death? Paying Equal Respects in Fijian Funerals}

\author{
Matti Eräsaari
}

\section{Introduction}

The 'good life' is an equivocal idea. It is routinely evoked in reference to one's material circumstances and abstract ideals, to signify future hopes ('I want the good life') and to critique a faulty present ('not a life worth living'). It also acts as a stamp of approval on present achievement ('this is the good life') and as an evaluation of a past life ('she lived a good life'). Therefore, to talk of the good life is to pick a viewpoint from among a range of possibilities.

In Fiji, people commonly portray a village-based lifestyle as the already accomplished good life. I have been told countless times by people who want to show that life in Fiji's villages amounts to an affluent paradise that 'everything is already here'. Yet, the majority of people born to a village end up living most of their lives elsewhere, and even those who remain in their home villages often express a preference for an urban life. In the village of Naloto, Verata, just outside Fiji's main metropolitan area, the preference for urban careers is most often seen in terms of necessity, due to the better schools and other opportunities available outside the village; however, the money from tourist resorts, or careers in civil service, also has a pull beyond the merely pragmatic. 'Some people dream about a good job in town; others dream of getting respect by drinking yaqona 
[kava]', a Naloto village man in his early 30 s told me. This is a starting point that epitomises two key positions in an ongoing discourse on the good life. What the village man was telling me was that one can either seek the esteem of fellow villagers by maintaining a presence in front of the village community or one can seek success outside the village.

In this chapter, I adopt a village-centric viewpoint in which the home village acts as a centre and organising principle for the greater village community, which includes the village residents and its emigrants alike. Most indigenous Fijians are registered as members of the landowning groups in their village at birth; it is to the village that most seek to retire at the end of their careers, and it is the village of their birth, or the one they married into, where they are eventually buried. Indeed, it is specifically by looking into funerals that I seek to foreground what it means to be respected by the community. In short, my starting point is the posthumous recognition of a good life.

In Metcalf and Huntington's (1999, p. 24) words, 'the issue of death throws into relief the most important cultural values by which people live their lives and evaluate their experiences'. As far as the elaboration of shared values is concerned, it seems safe to say that indigenous Fijian culture gives considerably more attention to funerals than other rituals, such as weddings. Funerals are big, public affairs, the preparations, exchanges and distributions of which involve entire villages. This is also to say that the issue of death is not shunned or brushed aside; when death occurs, local and international extended kin networks are called quickly into action. Funerals concern people on a wide scale, and even though weddings are currently growing in size, the ideal, typical wedding remains a relatively small-scale affair conducted largely between two families. Even the largescale rituals held to legitimise the now prevalent elopement marriages, which in Naloto are routinely combined with the presentation of children to their maternal kin (see Eräsaari, 2013, pp. 172-76; Pauwels, 2015; Williksen-Bakker, 1986), always have to give precedence to funerals. This may be partly because a death, unlike a marriage celebration, cannot be rescheduled; however, it also reflects the wider scope and general sense of obligation that a death stands for. Such a sense of obligation is perhaps best conceptualised by Barraud, De Coppet, Iteanu and Jamous's (1994) notion of 'life credit' and its closure or 'summation' at funerals (pp. 35-39). The funeral acts as a public acknowledgement and repayment of debts to the deceased. 
Fijian funerals, at least implicitly, embrace a parallel idea wherein the number of groups attending is seen as recognition that the deceased had previously come to the aid of others. During my fieldwork in Naloto village in 2007-08, I often heard people talking about this in the context of past funerals; they generally sought to estimate the number of groups that had arrived to pay their final respects. This, in the final analysis, was the indicator that someone had lived a good life. The number of arrivals is the key data recorded at funerals. The anthropologist, Tuomas Tammisto, who conducted fieldwork among the Mengen of New Britain, once told me about a moment during fieldwork when he realised that the participants of ceremonial exchanges were not only producing multiple lists of the things exchanged, but that their lists were more accurate than the ones he had compiled. I was similarly preoccupied with listing things given and received on ritual occasions during my fieldwork, and my lists were occasionally even used by the organisers - not to ascertain the quantities that I had carefully documented and my hosts marked out in generics, but to make sure that the participating groups were all accounted for.

A funeral sums up a person's life: the times they did their duty towards others and when they came to others' aid in times of need. Being socially active in life is acknowledged in the number of groups that come to pay their final respects to the family of the deceased. However, a focus on the groups that arrive at funerals calls further attention to how they pay their respects, and here we are faced with a significant change in comparison to what has generally been reported in Fiji in the past. For instead of expressing a pre-established difference between the groups involved, the funeral gifts in Naloto that I witnessed established the similarity, even equality, between the parties participating in the funeral exchanges; in doing so, they revealed the degree to which a funeral might be regarded as an index of the relatively equal relations one has had in one's lifetime. This represents a major departure from the traditional values of chiefly East Fiji, a difference that is highly salient for understanding not only death, but the good life too.

By pursuing the meaning of the good life in death rituals, my aim is to highlight an emergent ideology that informs not only the ceremonial life, but also the lifetime ambitions - 'career choices' — of the people I worked with. Rather than saying that Nalotans place high value on dying, or that their life ambitions are geared towards funerals, I want to show that Nalotan funerals have come to be social occasions that reveal a significant change in the types of relations people consider relevant. I will be arguing 
that these funerals display a shift, from a pattern of differentiating exchanges between people marked out by pre-existing hierarchical difference, to exchanges characterised by symmetrical reciprocity. This chapter tries to point out how such a pattern, found in a place often regarded as the home of the major chiefly families in Fiji—a heartland of Fijian chieftaincy-reflects wider changes that have occurred in Fiji gradually over a number of decades. I present my argument by first contextualising Naloto village, then describing Nalotan funeral exchange, before focusing on the most visible part of funeral gifts: the whales' teeth. I then highlight the significance of Nalotan funeral practice in contrast to Tongan concerns with rank and differentiation. This will allow me to comment, in conclusion, on the limits of the emergent ideology expressed through the funeral rites - that is, the extent of the egalitarianism and the new spaces of distinction it carves out.

\section{Naloto Village: Historical and Ethnographic Context}

Naloto is one of the seven villages that make up the chiefdom of Verata on the east coast of Viti Levu island, roughly an hour's drive north from Nausori town. Just outside Fiji's main metropolitan area-the so-called Suva-Nausori urban corridor-Naloto offers no daily access to urban Fiji: it is too deep in the forest, the gravel road does not support buses and there are no cars in the village. On most days, a lorry goes from Naloto or the neighbouring villages to Korovou town, Nausori or Suva; however, it is neither regular nor fast enough for a job in town. Most village households sell their produce at the Nausori or Suva marketplaces on weekends, but this is considered supplementary income; people in the village maintain a semi-subsistent lifestyle, getting most of their daily food by farming, fishing and gathering wild produce.

Farmland is abundant in the village; even the kin groups who hold the least agricultural land per capita (see Eräsaari, 2013, pp. 18-39) have enough to subsist on. For the majority of villagers, life in the village represents an ideal - a lifestyle based on neighbourly sharing, subsisting on the land and, most importantly, having no need for money. From this highly idealised point of view, the 'good life' is a reality for indigenous Fijians living in their native villages. 
However, although rich in land and food, the village lacks easy access to money and market goods, ranging from necessities such as clothing and building materials, to consumables such as DVDs and instant noodles. Raising money in the village is hard. Young families that need to accumulate the essentials of an independent household frequently move away from the village to work in the urban market, often in the hope of putting their children in good schools as well. In fact, while Naloto village - the largest of the seven Verata villages-boasts a population of around 300 people, the number registered as Nalotan landowners (but not living in the village) is roughly $600 .{ }^{1}$ Especially for young villagers, moving to town for work is practically a life cycle expectation, just as most expect to retire back to the village with enough earnings to set up a house and lead a comfortable village life. However, for those who never attain urban employment, the village may become synonymous with failure: 'the last place', as one villager phrased it. In other words, there are two conflicting views on village life; it is either a paradise of fulfilled needs or a bare-bones existence without development or 'moving forward' (toso).

Naloto is the focal point of an extensive network of emigrant villagers living in urban centres or working in tourist resorts, with many more living overseas on other Pacific islands or in Australia, the US or even Europe. These emigrant Nalotans participate in the life of the village by supporting their close village kin with money and gifts, in communal development projects through fundraisers and by taking part in village events when they are able. ${ }^{2}$ Absentee villagers remain affiliated with Naloto and the encompassing chiefdom of Verata even after residing elsewhere for generations. Access to village land is an inalienable right that is usually passed down from father to children; however, one's home village is also a source of identification that predetermines certain collective relationships between villages, chiefdoms and precolonial 'confederations'.

The protocol associated with one's home village combines traditional categories for classifying relations between places—such as bati (warrior ally), tauvu (common origin), veitabani (descendants of cross-cousins) and so forth-with a system of ranking among the chiefdoms of Fiji. Regardless of whether one has ever even visited one's home village, a place

1 Both figures are from 2008. The number of village residents is from the administrative headman's (turaga ni koro) records; the number of people of Nalotan descent comes from the register of native landowners (Vola ni Kawa Bula).

2 It is typical to try and organise big fundraisers and 'pre-arrangeable' life cycle events during public holidays to make it possible for the emigrant villagers to participate as well. 
of origin determines the terms of address and appropriate behaviour in certain relationships, as it does one's place in the order of precedence applicable in formal meetings, kava drinking and so on. The chiefdom of Verata occupies a unique place in the national mythology; it is one of the most widely agreed upon origin places for the chiefly families of Fiji-a heartland of Fijian chieftaincy, which stands for seniority and gravitas. While there are high chieftaincies that outrank Verata in power and prestige, Verata is nonetheless commonly recognised as the original home of the chiefly houses of East Fiji, a status to which other chiefdoms also pay homage. For example, in the aftermath of the December 2006 military coup, Nalotans reported circulating prophecies foretelling the arrival of peace and wellbeing for the nation accompanying the rise of a true leader from Verata.

However, while the symbolic status of Verata and its chiefs remains high, chiefly authority does not. This has been accentuated in Fijian politics since the 2006 coup, wherein chiefly politics has been challenged more generally; the interim government's power struggle with Fiji's Great Council of Chiefs finally resulted in the council's formal disestablishment in 2012. Coup leader Bainimarama's sustained campaign against the constitutional role of chieftaincy in Fiji has been carried over to his postelection politics as prime minister.

The political campaign against the official status of chieftaincy has been prefaced by significant shifts in the political, economic and even cosmological underpinnings of chieftaincy. Not only have the chiefs lost their status as superhuman others ('stranger kings'), they have also lost their standing as landless 'guests' distinct from common people, a distinction elaborated in traditional chiefly installations (cf. Eräsaari, 2015; Hocart, 1929; Sahlins, 1985). In 2008, it was estimated that over 80 per cent of chiefs in Fiji had not been traditionally installed (Vunileba, 2008), a figure including paramount chiefs such as the Vunivalu of Bau or the Ratu of Verata.

The same applies to the Naloto hereditary chieftaincy, the Komai Naloto title. The title is one of numerous chiefly titles that have foregone the traditional installation ceremonies and reverted to hereditary succession. Naloto has effectively abandoned the ritual of installing-'making' (buli) - the chief, wherein a 'kingmaker' clan elects the new chief who is installed in office by a group of specialists. Neither of these specialist groups are part of the chiefly clan; rather, they represent a typical Fijian 
ritual arrangement into opposed sides that recurrently create a whole community out of two dichotomous halves, sides or ritual moieties. Installed chiefs, I was told, bore the title of Ratu, whereas the current hereditary titleholders are 'just komais', as a Naloto woman put it: holders of an inferior title.

Indeed, the komai title is not a very coveted one in Naloto. Before it was bestowed upon the current incumbent, it was apparently refused by another, and possibly several senior members of his lineage, just as in the previous generation the title was handed over to another lineage because no one in the chiefly lineage wanted it. Many in Naloto claim that the rightful heir to the chieftaincy actually lives on another island, in a village now blessed with prosperity, while, in Naloto, left for generations with a junior lineage, things are changing for the worse. This is another way of saying that the villagers, despite feeling let-down by their own chiefs, still yearn for a powerful, authoritative chief like the chiefs of old (cf. Tomlinson 2009).

The diminished title is paralleled by the respect and authority awarded the chief. The Komai Naloto may be acknowledged as the head of the village, but is often ignored in actual decision-making and disobeyed when giving commands. The old chief responds by refusing to play the chief's part in church services or formal events. The head of the Naloto 'sea people' (Na Tunidau) fares somewhat better, though, like the village paramount, also carries little authority. Indeed, in 2008, the sea chief became so infuriated by the lack of respect shown to him by his people that he moved to the capital. Rather than apologising or requesting his return, most of the people in the sea moiety found this amusing.

In 2008, Nalotans had various opinions as to why their chiefs commanded less respect than they used to. Some urban Nalotans thought it was their village-based relatives' tendency to put on airs that resulted in the belittling of the chief. 'Today, everybody wants to be the chief, to drink first', a Naloto man based in the Western Province explained with reference to the hierarchical order of serving kava. Others blamed the kava itself, claiming that the village elders were unable to give commands; they 'stay up too late and wake up late', one of the village-based youths put it, again with reference to kava drinking. Some blamed the division of labour in the village, pointing to the failure of the chief's 'constabulary' (bati lekaleka) to make sure that his commands were obeyed. Still others blamed food; a few claimed that the Fijian people were deteriorating as 
a consequence of eating too much bread and noodles and were generally less commanding than their ancestors. Others thought that the problem was the large-scale discontinuation of food taboos separating 'nobles' from 'commoners' in Naloto. Predictably, money and individualism acted as the most popular scapegoats, even if no one could pinpoint, specifically, what it was they did.

While the villagers could not agree on the causes of weak leadership in the village, their own actions revealed its wider structural underpinnings. The funeral rituals discussed below justify such an opinion, for while they obviously give expression to key ideas of mutual aid and communal obligation, the formal features observed during these events throw into relief the absence of hierarchical markers in Nalotan funerals. In this sense, the 'enumeration' of final respects not only sums up a life, it also gradually undermines traditional ideas of rank.

\section{Egalitarian Ideology in Funeral Rituals}

Veratan death rituals span from the time of death to 100 nights after the burial. Here I focus on two key stages: the time reserved for paying final respects before the burial and the closing feast afterwards. It is during these stages that the hosting group welcomes the numerous groups of guests that arrive to pay their final respects to the deceased, gradually subsuming them before 'releasing' them to go their way after the burial. The exchanges that take place during these stages can be seen both as a summative index of the deceased's life achievement and an affirmation of the relationship between the groups that participate in a funeral. ${ }^{3}$

In Verata, the time of paying final respects-gauna ni reguregu (approximately, 'time for kissing goodbye') — is usually on the evening before burial. This is when numerous kin groups come to convey their condolences to the family of the deceased, each group presenting reguregu (from regu, kiss) gifts to the hosts in turn. The smallest funeral I witnessed in Fiji hosted only a half-dozen groups of guests; however, this funeral of an adolescent who had not yet accumulated social connections beyond the village community was a rare exception. The largest funerals I took part in involved more than 20 groups of guests, each presenting their funeral contributions one after the other.

3 For a description of Nalotan funerals, see Eräsaari (2013, pp. 176-79). 
The proceedings always follow a fixed protocol. The funeral guests begin by presenting their sevusevu (bundle of kava roots), which are offered in greeting to the hosts. After accepting this, the hosts, in turn, offer a sevusevu. It is customary for a group hosting a funeral to have a cardboard box of kava bundles standing by so they constantly have a number of appropriate items ready. In most of the cases I saw, the guests' spokesperson quickly gestures that they wish to forgo the bundle received in reciprocation, which the hosts' spokesperson usually accepts with a respectful hand clap (cobo) (see Arno, 2005). After this initial exchange, the visiting group's spokesperson offers their reguregu, a condolence gift brought to the family of the deceased. This usually comprises woven mats and a bark cloth accompanied by items of food: taro or cassava and some variety of meatpredominantly beef-or, alternatively, purchased items such as biscuits, bread and milk. All of these are represented by a whale's tooth (tabua) presented by the guests' spokesperson; this handheld token stands for the bark cloth, the mats, the roots and the meat-in ceremonial speech, it is 'the valuable with its wealth, its food, its relish'. The hosts reciprocate with a whale's tooth of their own to thank their guests for the gifts received, after which the arrivals take their place as part of the ever-expanding group of hosts as the next group arrives to present its condolences.

The group entrusted with the task of bringing the coffin home (weka ni mate) should be the last to arrive (although, in practice, latecomers may arrive even during the church service or burial on the following day). The weka ni mate are the guests of honour in the funeral and their arrival is accompanied by heightened formality. They are presented with a whale's tooth immediately on their arrival; this item, known as vakasobu (from sobu, to exit a vehicle, canoe etc.) is presented outdoors, often with car headlights lighting the event. Only a small group of the deceased's close kin go out to meet them while others wait in the meeting hall or under a canopy constructed for the event. Once they are all back indoors, the weka ni mate present the coffin to the hosts with one whale's tooth, known as yago ni mate ('body of the deceased'), and offer their condolence gift of mats, bark cloth and food with another whale's tooth, before receiving a tooth that stands for some taro and sometimes a pig, as well as the food prepared by the hosts for all the condolers. Once the coffin has been carried from the hall, the weka ni mate collect the mats upon which the coffin has temporarily been resting and roll them into a bundle, which they take away with them. 
The day of the burial completes the sequence. However, whereas the eve of the burial is marked by the repetitious arrival of gifts and establishing the funeral communion, the following day is about fission, albeit notably less ceremoniously. After a church service and the burial itself-in which many of the funeral guests do not actually participate- the hosts present the funeral feast, embodied by yet another whale's tooth, to all the guests. The feast comprises large quantities of tubers baked in an earth oven, beef 'soposui' (chop suey) and stew. Bigger funeral feasts often also have pork cooked in an earth oven. Sometimes there is fish too, but it is neither a compulsory core item nor reserved for particular groups of guests.

The whale's tooth used for offering the feast food sometimes also stands for a separate gift of raw meat known as 'burua', an offering in which the hosting group distributes a slaughtered bull among the visiting groups. If they wish to single out a group of eminent guests who have arrived from afar, they may sometimes also present pork, but this is quite rare. As a rule, the burua involves very little elaboration; there are no speeches beyond a spokesperson brusquely calling out which portion is for which group of guests. There are no reception speeches by senior men; youths simply carry away the portions for subsequent-equally unceremoniousredistribution among the visiting groups. Most adult men then continue the funeral by drinking kava until a senior guest, such as the leader of the weka ni mate, requests permission to leave. He does so on behalf of all the funeral guests by presenting the hosts with a whale's tooth; the hosts reciprocate with a whale's tooth if they have one left, or with kava roots if not. Afterwards, the hosts distribute the mats and bark cloth among the assisting groups, before taking what is left themselves. In turn, the assisting and visiting groups divide their portions among their members. ${ }^{4}$

The funeral exchanges are conducted almost solely using a limited range of exchange media: kava, whale's teeth, bark cloth, mats, tubers, beef, pork and certain purchased foods, such as breakfast crackers, bread, milk and the like. This marks a departure from previous ethnographic descriptions of mortuary exchange in the area (Hocart, 1924; Ravuvu, 2005; Sahlins, 1976; Toren, 1988, p. 716, fn. 8), in which the focus has been on exchange between two kinds of people, both marking their relationship to the other by the use of relationship-specific exchange goods.

4 Final distribution is typically carried out by women, while the various stages of pooling preceding and during the funerals are supervised and conducted by senior men. 
The paradigmatic example of such relationship-specific exchange media is in funeral exchanges between groups designated as 'chiefly' (turaga) and 'warriors' (bati). These designations largely overlap with a division into 'sea people' and 'land people' found throughout indigenous Fiji. I have discussed these in greater detail elsewhere (see Eräsaari, 2013); here I will merely point out that this binary classification has traditionally been connected with the institution of landless foreigner chiefs and their landowning subjects. It also connotes ritual moieties, occupational specialisation in sea- and land-based produce, as well as a more general dichotomy of hosts (taukei) and guests (vulagi). The host-guest dichotomy retains an association with local land ownership vis-a-vis immigrating affines; however, the 'guest' category now commonly refers to recently arrived wives, or to the islands' devalued ethnic others, rather than the foreigner chiefs for which Fijian ethnography is better known. Hocart (1924, p. 186) perceived the relationship between 'warrior' and 'chiefly' groups as characterised by irreversible, differentiated obligations and privileges that were highlighted in food exchanges and eating prohibitions: the land people (Hocart's 'hill tribes') should provide pork to the sea people (Hocart's 'nobles') and abstain from eating it in the presence of the latter; the sea people should provide fish to the land people and abstain from eating it in their presence. These prescriptions were particularly associated with funerals, in which predetermined relations between groups were thereby perpetuated.

Hocart (1924) showed how these relations were superscribed on the map of north-eastern Viti Levu island, so that inland polities were 'land people' in relation to the people seaward of them, but were 'sea people' for the people landward of them. Hence, it is possible to read the traditional polities of the area as a sequence of land-sea relations bounded by the Kauvadra range in the interior and the coastal chiefly polities on the seashore. Within this scheme, Naloto is not only a coastal village, it is also part of the chiefdom of Verata, whose chiefly house is reckoned senior among Fiji's chiefly families. In many ways, Verata is 'as sea as can be', just as the Vatukaloko people living by the Kauvadra range can be said to represent the other extreme, ultimate land (see Kaplan, 1995). Adding to this, the people I lived with during my fieldwork, the Naloto sea moiety, represent 'sea' in the intra-village version of the dichotomysea within sea, so to speak. When asked to explain what being 'sea people' means, most resort to the food exchanges and eating prohibitions: 'we are sea people, we don't eat fish with the land people'. 
Yet, the exchange items classified as 'sea'-fish and other saltwater produce-were almost completely absent from the exchanges between land and sea people during my fieldwork, not only in the intra-village funeral exchanges between the Naloto chief's local land warriors (bati lekaleka) and sea people (kai wai) but also, notably, from the much more formal inter-chiefdom relations between the Veratans and their traditional allies (bati balavu) in the chiefdom of Vugalei. ${ }^{5}$ In both instances, instead of exchanging fish and pork, the two sides exchanged beef for beef-slaughtered bulls for stew (stiu), beef chop suey (soposui) and raw meat (burua). To be more precise, pork, the ceremonial due of chiefs, still persists as something with which a special guest of honour may be honoured. However, fish, the sea people's contribution, has virtually disappeared from traditional exchange, along with the accompanying eating prohibitions. ${ }^{6}$

People may go to great lengths to avoid putting themselves in the marked position of noble/guest/sea people; for example, some sell fish in town to convert it into other types of food. Even outside the funeral context, the sea people's ceremonial presentations are never made, as protocol requires; although the Naloto bati have repeatedly requested gifts of fish that the landsmen would reciprocate with whale's teeth (bati ni ika), the sea people take no heed of such requests. Tellingly, on a day when the prescribed chiefly 'sea' offering actually was taken to a funeral in Vugalei, the Naloto man responsible for the funeral gift was too ashamed to speak when offered a whale's tooth in reciprocation. It was as if presenting things 'downwards' from a 'chiefly' position was no longer considered appropriate, while whale's teeth, which are ceremonially always presented 'up' to the gentleman (turaga) overseeing the proceedings, seem to abound.

\section{Exchanging Whale's Teeth}

Whale's teeth are sometimes known as ulu ni yau, the 'head of valuables'. The expression indicates their singular status as the highest ranking of traditional Fijian wealth items. The ceremonial language used in Naloto

5 The traditional chiefdom and coinciding administrative district of Verata comprises seven villages of which Naloto is one. Verata's inland neighbour, the chiefdom/district of Vugalei, comprises nine villages.

6 Although everyone in Naloto knows of the eating prohibitions, only a few people follow them. Nalotans are aware of the fact that in more traditional places in Vugalei the eating prohibitions are still observed. 
classifies all valuables into six categories. Kamunaga (valuable) is only used for a whale's tooth during a ritual event. Yau (wealth) is used in reference to kava, bark cloth, mats and certain items associated with a particular region, as well as a limited range of store items, from print cloth and kerosene to washing powder and soap bars; it is also used for money on the rare occasion that money enters the ceremonial sphere. Magiti (feast food) refers to the tubers or plantains that are part of most ceremonial presentations and sometimes refers to purchased chop suey ingredients, such as carrots, onions or pak choi. I coi (relish) refers to the meat given as part of the presentation. Nalotans are familiar with more specific terms for the meat items discussed above-wai tui (saltwater) for fish and uro (fat) for pork; however, these are used only rarely and people say they are in the process of being replaced by the more general $i$ coi (cf. Eräsaari, 2013, pp. 169-70, fn. 63). In addition, the category wai katakata (hot water) may be used in reference to tea, milk, bread, butter, crackers, sugar and flour. For small, informal occasions, kamikamica (sweet) may be used for snacks brought along as an accompaniment to kava.

A typical Naloto funeral gift (reguregu) consists of a whale's tooth, kava, bark cloth, pandanus mats, taro, cassava and beef. This reflects the fact that ceremonial gifts are given by groups rather than individuals; the items are pooled together in events known as vakasoso yau (from soso, 'to exchange', 'to replace' and yau, 'wealth') that are organised separately by each participating group before the more formal funeral rites. In these events, each group - usually a clan, sometimes a moiety or representatives of an entire village-brings together men's wealth (kava, whale's teeth and usually the food items) and women's wealth (bark cloth and pandanus mats) to combine the parts into a gift that represents the whole group. Regardless of the pre-existing relations between the two groups-the hosts and the guests- the contributions are always the same.

Not only that, over the course of the funeral proceedings, gifts tend to be reciprocated in kind. I mentioned the initial identical exchange of kava bundles preceding the presentation of reguregu at funerals; I also showed how the distinction between proteins classified as 'fat' and 'saltwater' has been levelled to mere 'relish'. 'Moreover, although the exchange of identical bundles of pandanus mats is not customary in Naloto,

7 The distinction between raw and cooked food does not appear to be particularly significant in Naloto. 
as is the case among their neighbours in Vugalei, funerals nonetheless see participants giving and receiving identical media: mats, bark cloth and tubers in addition to the above mentioned items. Further, the language of ceremonial presentations not only uses generic categories for the kinds of things presented, it also employs indistinct units of accounting - sets and bundles-and participants make full use of every opportunity to belittle their own offerings. One consequence of this is that there may be genuine uncertainty about what a gift actually consists of, with most participants sitting on the ground hearing simply that the gift includes a 'valuable', some 'wealth', 'feast food' and 'relish'; the muddy or bloody foodstuffs often remain outside the ceremonial space, while the mats and bark cloth are rolled into bundles that are only opened after the funeral. The focal point of the ceremony-the one object explicitly displayedis the 'head of the valuables': the whale's tooth.

Tabua are different from all other exchange items; they outrank everything else in prestige. A tabua has executive power unlike any other. A tabua is always presented for a nominated purpose-to propose or finalise a marriage, to ask forgiveness, to pay final respects and so forthand, once accepted, it effects that purpose. Hence, the presentation and, especially, the reception of whale's teeth follows a protocol that is more formal and complicated than in other ceremonial exchanges.

A tabua is presented by the gift-givers' spokesperson who lists the traditional titles present in the event and states the purpose of the object, before handing the object over and returning to their place. The object is then conveyed to the head of the receiving party who accepts (ciqoma) it with a few words. The acceptance is followed by an elaborated pronouncement (kacivi) from the receiving party's spokesperson who again lists the titles in attendance and announces the accepted object's effect. Indeed, in idiomatic Fiji English, one does not 'give' or 'exchange' a tabua-one 'does' a tabua. The performative power of whale's teeth comes out at the final exclamation ending the proclamation of acceptance, 'Mana! E dina' ('Effective. It is true'), the last words chanted in unison by everyone in attendance as the object takes effect.

This is why a tabua always has to be accepted by a chief. Whale's teeth are the only objects personally received by a senior titleholder in the receiving party; when a presentation does not include a tabua, it is received by the chief's spokesperson. Whale's teeth are the only objects that are accepted 'twice': by a chief of the receiving party and by their 
spokesperson. This means that the receiver of a tabua is always a chief. Whether the head of a household or sub-clan, or the senior representative of the chiefly lineage, the receiver will always assume a title and be the chief in attendance. The entire process of 'doing' a tabua is geared towards the reception-right from the ritual cry $(\operatorname{tam} a)$ made to introduce the valuable, down to the honorific terms of address used for the recipient. Indeed, it has been pointed out that the presentation of a tabua elevates the recipient above the giver; it is the supreme honour, but also the ultimate expression of loyalty and even submission, that a group can make (see Hooper, 2013, p. 106). The presenter of a tabua is, quite literally, paying respects to the recipient.

It is here, at the point at which both the prestige and ritual elaboration of the exchanges are at their highest, that the like-for-like pattern of exchange also becomes the most pronounced. I described above how every tabua received as a condolence gift in a Naloto funeral is immediately reciprocated with another, similar object, usually labelled simply vakavinaka na yau ('in thanks for the wealth'). While the guests of honour are obliged to present two whale's teeth-one accompanying the casket, the other their reguregu gift-they also receive two teeth: one upon arrival, the other in thanks for the gift. At the end of the funeral, when it is time to break-up the funeral communion, the leader of the guests presents a tabua when requesting permission to leave (tatau) and this, too, is reciprocated with a tabua, simply labelled vakatale ('likewise' or 'return'). If I were to lay out examples of marriage exchanges, it would become obvious how much manipulation may be involved in keeping the number of tabua given and received equal: when to give two objects, when to perform two in succession or when to give none (see Eräsaari, 2013, pp. 137-49). However, in a funeral, when the average group presents its gift with a single tabua, they also receive one, or, if they present their gift without one (in which case a bundle of kava roots will act as the focal point), they also receive none in return.

In the historical literature, the reciprocation of tabua with tabua seems to exist only in the practice of cancelling (dirika) one tabua with another. A whale's tooth presented as a dirika carries no cause or purpose except to cancel the effect of one tabua by giving another. It is a practice known in Naloto; however, to my knowledge, it is restricted to the sole situation where a man has left behind a widow. On such an occasion, the woman's kin, in offering to take her back to her natal family, present a tabua during the funeral. It is customary in Naloto to dirika such an offer. Although it 
sometimes occurs that an unpopular wife or woman with no offspring may be allowed to return, it is such a rare and marked practice that it merely serves to illustrate how very untypical it is in Naloto to not reciprocate whale's teeth.

I am not saying that every traditional event ends up being even. 'You might not get a tabua back', I was sometimes reminded regarding the risks involved in ceremonial exchange. However, that, too, ultimately highlights the assumption that one is very much expected to get as good as one gives. Compare this with Hooper's (2013) account of tabua use in the Lau group in Fiji in the 1970s. Hooper was explicitly told that presenting whale's teeth in combination with other categories of exchange items (such as food), and the undiscriminating reciprocation of tabua with tabua, regardless of context, went against received protocol (pp. 122, 129). Yet Hooper also pointed out that it is members of chiefly clans who should present and receive tabua (p. 110). Conversely, in Naloto, it is said that every man should be in possession of a tabua in case he might need one; by the same token, every man is said to be a chief in his own house.

\section{Equal and Unequal Exchange}

This is where I finally pick up the topic of the good life by way of pointing out what a strange thing it is to be spending one's resources on the equal exchange of things of the same class or of identical things. These, Forge (1972, p. 534) once argued, can be viewed as 'the principal mechanism by which equality is maintained'. Joel Robbins, developing Forge's idea in his 1994 essay on 'equality as a value', likewise regarded equal exchange to be 'the mechanism which produces value' on the condition that 'what Melanesians value in exchange is equality' (Robbins, 1994, p. 39). Naloto funerals, too, express and reproduce balance and equality rather than hierarchy and distinction. I have elsewhere argued that in Naloto the appearance of egalitarian exchange corresponds with the disappearance of a binary distinction between autochthones and strangers (see Eräsaari, 2013, 2015). Here I want to go further, pointing out how the lack of interest in quantitative valuation produces relatively egalitarian relations among exchange partners.

Let me give a comparative example. Douaire-Marsaudon's (2008) analysis of the exchange of food ( $k a i$-i.e. pork and tubers) and wealth (koloa-i.e. mats, bark cloth and coconut oil) in Tonga and Wallis drew 
on, and thereby highlighted, an astounding degree of attention paid to the quantification of exchange goods. From the early nineteenth-century material onwards, Douaire-Marsaudon was able to comfortably list staggering amounts of food used in ceremonial exchange- 14 tonnes in the three instances discussed. What made such precise quantification possible was that all contributions were carefully enumerated during the ceremonies, and people paid close attention to this. 'Piling up, distributing and destroying food', Douaire-Marsaudon explained:

Are also designed to make clear to everyone who is who: in effect, a chief accumulates and distributes more than an ordinary man. His wealth and his liberality are measured first of all in food ... from the bottom to the top of the Tongan social pyramid: each must make gifts to his hierarchical superior, and first of all gifts of food, if he wants to maintain his rank [emphasis added]. (p. 211)

The same happens with traditional wealth. 'The amount of cloth and mats collected are indications of the wealth and station of the families', to which end 'gifts are solemnly enumerated and counted before being distributed' (p. 215). Even today, despite what Douaire-Marsaudon regarded as the equalising influence of Christianity, events that include the presentation of ceremonial wealth can become highly competitive. All of this is indicative of the way that power is realised in Tonga and Wallis 'in terms of "wealth"' (p. 217). Gifts of food and wealth are a powerful medium for competition among relative equals who need to make explicit their status differences, and for maintaining pre-established differences among unequals.

Douaire-Marsaudon (2008) demonstrated that this mattered to onlookers as well. People expect the chiefly redistributions to match the original contributions; in this way, the enumeration can be seen as a form of accountability. Money contributions are not particularly problematic in Tongan and Wallisian ceremonial exchange, as quantification is an inherently important aspect of traditional exchange. However, the custom of placing money contributions in envelopes is problematic. Presenting money in an envelope, hidden from sight, places it beyond the usual social controls; thus, it may be put in the bank and kept for personal use instead of being redistributed (p. 223). In short, the ceremonial preoccupation with quantities in Tonga and Wallis serves the purposes of status competition while simultaneously providing a measure for redistribution. 
In Naloto, cash envelopes are part of ceremonial exchange on the rare occasion that money is used in such exchange. Rather than standing in opposition to established custom, they reflect the prevailing Nalotan preference for non-quantification and undifferentiation (cf. Autio, 2010) among participants. Yet, the assertion of egalitarian practices in which chiefly prestige has traditionally been displayed does not make all Nalotans equal-it simply means that rituals of status verification take place elsewhere.

In Naloto village, such a context can be found in the abundant fundraisers that form the basis of public welfare. The school, community hall, water pump and other common utilities are made and maintained through public fundraisers, which the villagers, as a rule, treat similarly to ceremonial exchange: participants meet a preordained sum precisely, everyone making identical donations. Hence, the fundraisers, as events, tend to be similar to traditional ceremonies in the sense that both are timeconsuming affairs in which people take turns making similar or identical presentations. However, the fundraiser format pays particular attention to quantity (see Eräsaari, 2013, pp. 194-207). By publicly listing and announcing the precise quantities presented by individuals rather than groups, fundraisers favour emigrant villagers who have easier access to money and who do not participate in village fundraisers on a weekly basis. In other words, they provide an occasion for the transient visitor to make an impression.

\section{Conclusion: 'A Good Job in Town'}

I have briefly evoked the fundraisers here to highlight the contrast with funerals. The funerals discussed in this chapter show that Nalotans have adopted a form of exchange that practically counters the chiefly system for which the whole polity of Verata is famous. As employed during funeral rites, these exchanges act as an evaluation of a life lived, providing a summative account of the merit due to the deceased and his or her kin group. Hence, these ceremonial exchanges make the 'worth' of a person's accomplishments known to posterity-a clear indication that the ancestors still comprise an important part of the Fijian kinship system, as has recently been argued (e.g. Hulkenberg, 2015; Cayrol, 2015). However, for the living, what is given and what is received are too closely matched to act as a medium of status rivalry among the participating groups. 
Yet, this does not mean that we ought to limit our final analysis of equal exchange to a mechanical functioning of gifts and counter gifts or the annulment of gift debt and hierarchical relations. For although Fijian equal exchange does not produce the verifiable status differences described in Douaire-Marsaudon's (2008) Tongan and Wallisean examples, one should not assume that an egalitarian form of exchange produces 'equality' per se. Gregory (2014) took up this topic in his Anthony Forge Memorial Lecture, in which he called for more attention to the historically situated realities of egalitarian or 'democratic' ideals in postcolonial settings such as Fiji and Papua New Guinea.

In Fiji, such historical circumstances include the often-significant quantities of agricultural land available to indigenous landowning clans. In areas such as Tailevu province, of which Naloto is a part, the availability of land results in a lifestyle in which the village offers a safe backdrop or 'safety net' that can be counted on for the provision of the basic necessities of life. However, these egalitarian conditions also give rise to the choice that young men, in particular, face: 'some dream about a good job in town, others dream of getting respect by drinking yaqona', as my friend phrased it.

From a village-centric viewpoint, the choice may indeed be concretised as kava drinking versus urban employment: sitting still with others versus paid employment away from the village. However, the exchanges accompanying the kava drinking reveal a set of egalitarian, rather than chiefly, practices at the ceremonial core of village life, in which one would assume chiefly hierarchy to preside. Still, the absence of a marked hierarchy in this one (albeit traditionally very significant) sphere, does not pre-empt the possibility of status distinction in other contexts or spheres. This should be particularly evident in a time when the constitutional underpinnings of chiefly power have been discontinued (Bainimarama, 2012) and the use of chiefly titles in parliament have been banned; even the senior title-holding member of parliament makes nothing of it, because, in her words, 'we are all equal' (Swami, 2015).

The withdrawal of chiefly influence in national politics demonstrates how reputations are made with money donations and other nontraditional gifts. This was evident to me from the beginning of my fieldwork in Naloto in May 2007; making a voluntary contribution at a school fundraiser led villagers — so I was later told—-to view me as a decent person who recognised their need. The same fundraiser gave 
a well-known politician, a member of the pre-coup government, access to the village. After donating hundreds of dollars, instead of the required FJD65, he was garlanded and treated to a place at the top of the kava ring, from which he addressed first one-half, then later the entire village, on the political situation following the 2006 coup. Subsequently, the villagers were keen to point out what a good and generous man he was; by coming to their aid and speaking words of encouragement in troubled times, he made a lasting impression on the village. Some months later, he led the villagers on a political mission that was not only an open show of support for the ousted government, but also a dangerous show of dissent against the military rule at that time.

There is a very strong ideology of what constitutes the good life in Naloto village. Although commonly expressed in terms of self-subsistence and sharing, the egalitarian implications accompanying the subsistence-based ideal come through on ceremonial occasions in a way that reveals the more wide-reaching notion of an undifferentiated village of similars. However, this extended village community of moneyed emigrants cannot be contained by the ideal model any further than the strict formalities of exchange. It is the latter that provides grounds for differentiating the village chieftains and the political leaders of Fiji, just as the egalitarian practices exemplified by funerals pave the way for new ways of signifying distinction.

\section{References}

Arno, A. (2005). Cobo and Tabua in Fiji: Two forms of cultural currency in an economy of sentiment. American Ethnologist, 32(1), 46-62. doi.org/10.1525/ae.2005.32.1.46

Autio, P. (2010). Hard custom, hard dance: Social organisation, (un) differentiation and notions of power in a Tabiteuean community, southern Kiribati. Helsinki, Finland: University of Helsinki. Retrieved from urn.fi/URN:ISBN:978-952-10-6151-6

Bainimarama, J. V. (2012, 14 March). Remarks by the Prime Minister on the Great Council of Chiefs. Retrieved from www.scoop.co.nz/stories/ WO1203/S00245/bainimarama-on-de-establishing-great-council-ofchiefs.htm 
Barraud, C., de Coppet, D., Iteanu, A. \& Jamous, R. (1994). Of relations and the dead: Four societies viewed from the angle of their exchanges. Oxford, England: Berg.

Cayrol, F. (2015). How would we have got here if our paternal grandmother had not existed? Relations of locality, blood, life and name in Nasau, Fiji. In C. Toren \& S. Pauwels (Eds), Living kinship in the Pacific (pp. 207-41). New York, NY: Berghahn.

Douaire-Marsaudon, F. (2008). Food and wealth: Ceremonial objects as signs of identity in Tonga and in Wallis. In S. Tcherkezoff and F. Douaire-Marsaudon (Eds), The changing South Pacific: Identities and transformations (2nd ed.) (pp. 207-29). Canberra, ACT: ANU E Press. Retrieved from press-files.anu.edu.au/downloads/press/ p90711/pdf/ch10.pdf

Eräsaari, M. (2013). 'We are the originals': A study of value in Fiji . University of Helsinki, Finland. Retrieved from hdl.handle.net/10138/40203

Eräsaari, M. (2015). The iTaukei chief: Value and alterity in Verata. Journal de la Société des Océanistes, 141, 239-54. doi.org/10.4000/jso.7407

Forge, A. (1972). The golden gleece. Man, 7(4), 527-40. doi.org/10.2307/ 2799947

Gregory, C. (2014). Unequal egalitarianism: Reflections on Forge's paradox. The Asia Pacific Journal of Anthropology, 15(3), 197-217. doi.org/10.1080/14442213.2014.916342

Hocart, A. M. (1924). Maternal relations in Melanesian ritual. Man, 24(132), 185-86. doi.org/10.2307/2787616

Hocart, A. M. (1929). Lau Islands, Fij. Honolulu, HI: Bernice P. Bishop Museum.

Hooper, S. (2013). 'Supreme among our valuables': Whale teeth tabua, chiefship and power in eastern Fiji. Journal of the Polynesian Society, 122(2), 161-210.

Hulkenberg, J. (2015). Fijian kinship: Exchange and migration. In C. Toren and S. Pauwels (Eds), Living kinship in the Pacific (pp. 60-86). New York, NY: Berghahn. 
Kaplan, M. (1995). Neither cargo nor cult: Ritual politics and the colonial imagination in Fiji. Durham, NC: Duke University Press.

Metcalf, P. \& Huntington, R. (1999). Celebrations of death: The anthropology of mortuary ritual (2nd ed.). Cambridge, England: Cambridge University Press.

Pauwels, S. (2015). The Vasu position and the sister's mana. The case of Lau, Fiji. In C. Toren \& S. Pauwels (Eds), Living kinship in the Pacific (pp. 143-64). New York, NY: Berghahn.

Ravuvu, A. (2005). Vaka i taukei: The Fijian way of life. Suva, Fiji: University of the South Pacific, Institute of Pacific Studies.

Robbins, J. (1994). Equality as a value: Ideology in Dumont, Melanesia and the West. Social Analysis, 36, 21-70.

Sahlins, M. (1976). Culture and practical reason. Chicago, IL: University of Chicago Press.

Sahlins, M. (1985). Islands of history. Chicago, IL: University of Chicago Press.

Swami, N. (2015, 11 February). PM: Out with insults in Parliament. Fiji Times. Retrieved from www.fijitimes.com/story.aspx?id=294671

Tomlinson, M. (2009). In God's image: The metaculture of Fijian Christianity. Berkeley, CA: University of California Press.

Toren, Christina (1988). Making the present, revealing the past: The mutability and continuity of tradition as process. Man (new series) 23(4), 696-717.

Vunileba, A. (2008, 1 April). Some chiefs not installed. Fiji Times (p. 4).

Williksen-Bakker, S. (1986). Ceremony and complication in an urban context. In C. Griffin \& M. Monsell-Davis (Eds), Fijians in town (pp. 196-208). Suva, Fiji: Institute of Pacific Studies, University of the South Pacific. 
This text is taken from The Quest for the Good Life in Precarious Times: Informal, Ethnographic Perspectives on the Domestic Moral Economy, edited by Chris Gregory and Jon Altman, published 2018 by ANU Press, The Australian National University, Canberra, Australia.

doi.org/10.22459/QGLPT.03.2018.02 